'Instituto Agronômico de Pernambuco (IPA), Av. Gal. San Martin, 1371, Bongi, CEP 50761-000, Recife, PE, Brasil

2Estação Experimental de Araripina,

Instituto Agronômico de Pernambuco

(IPA), Araripina, PE, Brasil

¿3stação Experimental de Itapirema,

Instituto Agronômico de Pernambuco

(IPA), Goiana, PE, Brasil

* autor correspondente

\felix.antonio@ipa.br

\section{Miranda IPA 207, Nova Cultivar de Feijão-Caupi para o Nordeste Brasileiro}

\author{
Miranda IPA 207, a new cowpea cultivar for northeastern \\ Brazil
}

Antonio Félix da Costa ${ }^{1 *}$, Maria da Conceição Martiniano de Souza', Vânia Trindade Barrêtto Canuto', Rodrigo Leandro Braga de Castro Coitinho ${ }^{1}$, José Alves Tavares², Manoel Américo Carvalho Fonseca ${ }^{3}$
RESUMO: As maiores áreas cultivadas de feijãocaupi no País localizam-se nas regiões mais adversas, contribuindo para o desenvolvimento local e na alimentação de suas populações. A busca por novas cultivares com características superiores implica a utilização de genótipos que, ao serem cruzados, suas descendências expressem esses atributos. As cultivares Vita 3 e CNCx 11-9D apresentam, respectivamente, ciclo médio-precoce e resistência à cigarrinha-verde e a potyvirus. O cruzamento desses dois genótipos deu origem à linhagem L.281.005, conhecida entre os agricultores da Região Nordeste como IPA 207. Depois do advento da nova legislação para o registro de cultivares, durante dois anos, e em quatro locais distintos, comprovou-se a excelente produtividade dessa linhagem quando comparada com as testemunhas Patativa e BRS Paraguaçu em Pernambuco.

PALAVRAS-CHAVE: Vigna unguiculata, cultivar, genótipos, melhoramento genético.
ABSTRACT: The largest areas cultivated with cowpea are located in the most unfavorable regions of the country, contributing to the local development of these areas and the feeding of their populations. The search for new cultivars with superior characteristics implies the use of genotypes that, when cross-bred, express these attributes in their progeny. The genotypes used in the bean improvement program, Vita 3 and CNCX 11-9D, show, respectively, early-medium maturity cycle and resistance to green leafhoppers and potyviruses. The intersection of these two genotypes gave rise to the L 281.005 strain, known among farmers in northeastern Brazil as IPA 207. After the new legislation for the registration of cultivars was passed, the excellent productivity of this strain was observed in comparison with the Patativa and BRS Paraguaçu witnesses in four separate locations in Pernambuco state for two years.

KEYWORDS: Vigna unguiculata, cultivar, genotypes, plant breeding.
A cultura do feijão-caupi é muito importante, por proporcionar o desenvolvimento local e por gerar empregos em todo o ciclo. É uma cultura que apresenta alto valor proteico na composição química dos seus grãos e também se adequa às condições ambientais mais adversas, devido, principalmente, à sua rusticidade. Os maiores produtores e consumidores dessa leguminosa estão concentrados nos países africanos, latino-americanos e asiáticos, nos quais predomina o sistema de agricultura de base familiar (FAOSTAT, 2012).

No Brasil, as maiores áreas destinadas à produção de grãos dessa espécie encontram-se nas regiões Nordeste, Norte e Centro-Oeste. Essa cultura no Nordeste caracteriza-se pela adversidade climática, baixa tecnologia, excesso de mão de obra e baixo percentual de utilização de sementes de qualidade (INSTITUTO..., 2012).

As cultivares utilizadas pelos programas de melhoramento de feijão-caupi em décadas passadas eram oriundas, em sua 
maioria, de comunidades locais e de centros de pesquisa, nacionais e internacionais. Essas cultivares eram fornecidas para pesquisa, quando demandadas, às instituições estaduais componentes do Sistema Nacional de Pesquisa Agropecuária (SNPA). Vita 3, oriunda do International Institute of Tropical Agriculture (IITA), localizado na Nigéria, introduzida pelo CENARGEN, e o genótipo CNCx 11-9D, que pertencia ao banco de germoplasma da Embrapa Arroz e Feijão, são exemplos dessa prática. Do cruzamento desses dois genótipos, efetuado em 1983, originou-se a linhagem L. 281.005, conhecida nesta última década como IPA 207.

A cultivar Vita 3, lançada para o Estado do Piauí, foi utilizada como progenitor masculino, por apresentar boa arquitetura de planta; ciclo precoce a médio-precoce (70 a 80 dias); vagens bem formadas com inserção no nível e acima da folhagem; porte semiprostrado; cor da flor, violeta; vagem com $20 \mathrm{~cm}$ de comprimento; 16 grãos de cor vermelha; e peso de 100 sementes, de $21 \mathrm{~g}$. A cultivar CNCx 11-9D, de grão cor creme, escolhida por ser resistente a potyvirus e à cigarrinha-verde, apresenta porte prostrado e excelente produtividade, chegando a produzir mais de $2.500 \mathrm{~kg} / \mathrm{ha}$. Em regime de sequeiro, no Sertão do Pajeú, experimentalmente, sua produtividade média foi superior a $1.700 \mathrm{~kg} / \mathrm{ha}$.

$\mathrm{O}$ avanço de geração das populações resultantes desse cruzamento ocorreu entre os anos de 1985 a 1987, em Estações Experimentais do Sertão do Pajeú e da Zona da Mata, com uma testemunha a cada cinco linhas. A seleção foi feita com base na avaliação visual das plantas e no peso das sementes de cada uma delas, tomando-se um valor de 50 gramas/planta, abaixo do qual aquela planta era descartada.

Em 1988 e 1989, foram conduzidas as gerações $F_{5}$ e $F_{6}$ em Estações Experimentais, situadas nas três Mesorregiões do Estado de Pernambuco, iniciando o processo de avaliação de rendimento, em ensaios com delineamento estatístico de blocos ao acaso, com quatro repetições, em um ou até cinco grupos de 18 linhagens e dois tratamentos comuns. Ao chegar a essas gerações, caracteres como doenças, cor, formato e tamanho do grão, porte e ciclo já haviam sido avaliados.

Entre 1990 e 1992, foram conduzidas as gerações $F_{7}, F_{8} e$ $\mathrm{F}_{9}$, respectivamente, em ensaios denominados de Linhas de
Elite, Ensaio Estadual 1 e Ensaio Estadual 2, com o mesmo delineamento anterior, nos mesmos locais, variando o número de tratamentos.

Em 1993, depois da seleção para todos os caracteres exigidos pelo mercado consumidor local, e daquelas linhagens consideradas candidatas a novas cultivares, foi produzida semente genética suficiente para compor quatro ensaios para o ano seguinte. Esses ensaios foram instalados com parcelas de $250 \mathrm{~m}^{2}$, em propriedades particulares dos municípios de Araripina e Serra Talhada, sendo uma das parcelas conduzida com uma cultivar local, escolhida pelo agricultor. O acompanhamento foi feito por todo o ciclo da cultura com a participação de agricultores locais, sendo a avaliação final realizada por eles, por intermédio de notas ou conceitos para várias características, da planta à semente. A linhagem L. 281.005 foi escolhida no ano seguinte, a partir de um novo ensaio avaliado por agricultores desses municípios.

Entretanto, a partir de então, houve um arrefecimento do programa de melhoramento genético de feijão-caupi do IPA, só retomando a programação normal em 2007, quando o País já contava com uma legislação nova, exigindo os ensaios para fins de determinação do Valor de Cultivo e Uso (VCU) para o registro de uma nova cultivar, conforme Portaria 294/1998 do Ministério da Agricultura, Pecuária e Abastecimento (MAPA). Esses ensaios foram conduzidos nos anos de 2009 e 2010.

Os ensaios de VCU foram instalados nas Mesorregiões da Mata pernambucana, Agreste e Sertão (Tabela 1), compostos por 20 tratamentos e quatro repetições, nos dois anos. Em Vitória, no primeiro ano, e Belém do São Francisco, o cultivo foi conduzido sob irrigação. Desse modo, pode-se observar o comportamento da cultivar tanto em diferentes mesorregiões quanto em duas épocas distintas, em regime de sequeiro e irrigado, totalizando oito ambientes. Os parâmetros avaliados foram comprimento médio de dez vagens $(\mathrm{cm})$; peso de dez vagens (g); número de sementes de dez vagens (unidade); peso de sementes de dez vagens $(\mathrm{g})$; peso de 100 sementes $(\mathrm{g})$; produtividade de grãos ( $\mathrm{kg} / \mathrm{ha}$ ); índice de grãos (relação palha x grão); dados da fenologia da planta.

Analisando-se os resultados dos ensaios de VCU, realizados em 2009, verificou-se que a linhagem L.281.005 apresentava

Tabela 1. Caracterização física das áreas de adaptação e época de plantio da linhagem L. 281.005, em diferentes ambientes do Estado de Pernambuco, quando avaliada nos ensaios de Valor de Cultivo e Uso (VCU).

\begin{tabular}{|c|c|c|c|c|c|c|c|c|}
\hline Localidade e Municípios & UF & $\begin{array}{l}\text { Altitude } \\
\text { (m) }\end{array}$ & Latitude & Longitude & $\begin{array}{l}\text { Temperatura } \\
\text { Média }\left({ }^{\circ} \mathbf{C}\right)\end{array}$ & Tipo de Solo & $\begin{array}{c}\text { Precipitação } \\
\text { Pluviométrica } \\
\text { (mm) }\end{array}$ & $\begin{array}{l}\text { Época de } \\
\text { Plantio }\end{array}$ \\
\hline $\begin{array}{l}\text { Estação Experimental de } \\
\text { Arcoverde/Arcoverde }\end{array}$ & $\mathrm{PE}$ & 664 & $08^{\circ} 25^{\prime} 00^{\prime \prime} \mathrm{S}$ & $08^{\circ} 25^{\prime} 00^{\prime \prime} \mathrm{S}$ & 22,5 & $\begin{array}{l}\text { Neossolo Litólico } \\
\text { Eutrófico }\end{array}$ & 666 & $17 / 08 / 2009$ \\
\hline $\begin{array}{l}\text { Estação Experimental de } \\
\text { Belém do São Francisco/ } \\
\text { Belém do São Francisco }\end{array}$ & PE & 305 & $08^{\circ} 45^{\prime} 00^{\prime \prime} \mathrm{S}$ & $08^{\circ} 45^{\prime} 00^{\prime \prime} \mathrm{S}$ & 26,6 & $\begin{array}{l}\text { Neossolo Flúvico } \\
\text { Eutrófico }\end{array}$ & 525 & $\begin{array}{l}28 / 07 / 2009 \\
04 / 03 / 2010\end{array}$ \\
\hline $\begin{array}{l}\text { Estação Experimental de } \\
\text { Itapirema/Goiana }\end{array}$ & $\mathrm{PE}$ & 14 & $07^{\circ} 34^{\prime} 00^{\prime \prime} \mathrm{S}$ & $35^{\circ} 00^{\prime} 00^{\prime \prime} \mathrm{W}$ & 25,0 & $\begin{array}{l}\text { Latossolo Vermelho } \\
\text { Amarelo Distróficos }\end{array}$ & 2.010 & $\begin{array}{l}16 / 07 / 2009 \\
30 / 03 / 2010\end{array}$ \\
\hline $\begin{array}{l}\text { Estação Experimental de } \\
\text { Vitória de Santo Antão/ } \\
\text { Vitória de Santo Antão }\end{array}$ & $\mathrm{PE}$ & 146 & $08^{\circ} 08^{\prime} 00^{\prime \prime} \mathrm{S}$ & $35^{\circ} 22^{\prime} 00^{\prime \prime} \mathrm{W}$ & 25,4 & $\begin{array}{l}\text { Argissolo Vermelho } \\
\text { Amarelo Eutrófico }\end{array}$ & 1.025 & $\begin{array}{l}04 / 08 / 2009 \\
25 / 03 / 2010\end{array}$ \\
\hline
\end{tabular}


comportamento superior quando comparada com as cultivares BRS Paraguaçu e Patativa, de maior expressão em áreas cultivadas no Estado, utilizadas como testemunhas, para quase todos os indicadores avaliados (Tabela 2).

Naquele ano, para todos os ambientes, independentemente do local, o comprimento médio de vagem, peso médio de dez vagens, número médio de sementes de dez vagens, peso médio de sementes de dez vagens e peso médio de cem sementes de Miranda IPA 207 foram superiores às testemunhas. Para 2010, no entanto, a linhagem L. 281.005 apresentou resultado inferior apenas em relação ao número médio de sementes de dez vagens, quando comparada à testemunha BRS Paraguaçu. $\mathrm{O}$ índice de grãos, dado que mede a relação grãos/palha na vagem, foi superior a $74 \%$, estando em um patamar intermediário em relação às testemunhas BRS Paraguaçu e Patativa, denotando que três quartos da massa da vagem são formados por grãos (Tabela 2).

A cultura do feijão-caupi é uma atividade de base familiar que emprega grande quantidade de mão de obra, especialmente na colheita. Destina-se ao consumo doméstico, especialmente no nordeste brasileiro, sendo, porém, comercializado o excedente. Cultivares que possuam os caracteres citados anteriormente atendem à demanda da agricultura familiar, no que a linhagem L.281.005 se destaca, por excelência.

Como pode ser observado, na Tabela 3, a linhagem L.281.005 apresenta comportamento regular e normalmente superior às demais, ficando abaixo das testemunhas apenas em 2009, em Itapirema, e para BRS Paraguaçu, no mesmo ano, em Vitória de Santo Antão. Em 2010, esta mesma cultivar foi superior à linhagem L.281.005, novamente em Itapirema.

Pode-se concluir que a linhagem L.281.005 possui resultados expressivos para as regiões de cultivo, podendo ser indicada tanto para a Mesorregião da Mata quanto para o Agreste e o Sertão, nos sistemas sequeiro e irrigado. Pode-se ainda estender sua indicação aos demais estados do Nordeste, baseado em dados comprovados por meio de publicações como resumos de congresso, artigos, monografias, dissertações e teses realizadas ao longo das duas últimas décadas.

A linhagem L.281.005 possui porte semiprostrado e apresenta coloração do hipocótilo, verde; da flor, roxa; e da folha no início do florescimento, verde. Quanto às características da semente, apresenta cor do tegumento, creme; do anel do hilo, marrom-escuro; e da membrana do hilo, marrom-claro. Apresenta ainda halo ausente; textura da semente, lisa; brilho, ausente; peso médio de 100 sementes varia entre 19,5 gramas a 21,0 gramas; ciclo médio da semeadura à floração, 40 a 45 dias; ciclo médio da semeadura à maturação de colheita de 63 a 68 dias. A vagem da linhagem L.281.005 tem um comprimento longo (como já discutido), possui antocianina com intensidade média, mais de uma cor quando madura, sendo a cor prevalecente avermelhada. Deve-se observar que o ciclo, porte e o peso de 100 sementes são muito influenciados pelo ambiente.

A linhagem L.281.005, conhecida no meio dos agricultores da Região Nordeste como IPA 207, foi denominada e registrada como Miranda IPA 2007, em homenagem, in memorian, ao pesquisador Paulo Miranda, melhorista de feijão, responsável direto pela sua seleção.

A partir da finalização do processo de seleção em 1995, essa linhagem está presente em diversos trabalhos de pesquisa, em vários estados do Nordeste, gerando monografias, dissertações, teses e artigos científicos.

Em Biotecnologia, Melo et al. (2011a) caracterizaram molecularmente cinco genótipos de feijão-caupi, utilizando os marcadores moleculares RAPD e ISSR, entre os quais, a linhagem L. 281.005, ressaltando que esta apresentou maior índice de similaridade com a cultivar BRS Pajeú. Oliveira et al. (2006) verificaram o efeito dos hormônios BAP e 2,4 - D na formação de calos com potencial regenerativo para a cultura in vitro, utilizando a cultivar de feijão-caupi IPA 207. Foi constatado que o melhor explante para indução de calos em feijão-caupi são os eixos embrionários.

$\mathrm{Na}$ área de fitopatologia, a linhagem L 281.005 (IPA, 207) contribuiu para a geração de algumas teses e também resumos em jornadas científicas. Andrión (2009) estudou em sua tese a supressividade natural de solos do nordeste brasileiro à murcha-de-fusarium e rizoctoniose do feijão-caupi, utilizando essa linhagem como hospedeira para avaliação. A indução da supressividade pela rotação de culturas no manejo da rizoctoniose do feijão-caupi foi estudada por Silva e Michereff (2010). Ferreira, Andrión e Michereff (2009) observaram a estabilidade da supressividade de solos à rizoctoniose do

Tabela 2. Valores médios de cinco variáveis da cultivar Miranda IPA 207, registrada junto ao MAPA, e de Patativa e BRS Paraguaçu, utilizadas como testemunhas.

\begin{tabular}{|c|c|c|c|c|c|c|}
\hline \multirow{2}{*}{$\begin{array}{l}\text { Variáveis } \\
\text { Avaliadas }\end{array}$} & \multicolumn{3}{|c|}{2009} & \multicolumn{3}{|c|}{2010} \\
\hline & Miranda IPA 207 & Patativa & BRS-Paraguaçu & Miranda IPA 207 & Patativa & BRS-Paraguaçu \\
\hline $\mathrm{C10V}(\mathrm{cm})$ & 22,39 & 18,45 & 20,64 & 23,78 & 20,06 & 21,15 \\
\hline P10V (g) & 45,71 & 36,19 & 33,36 & 39,72 & 34,06 & 33,67 \\
\hline NS10V (unid.) & 169,31 & 136,50 & 151,18 & 149,62 & 129,43 & 151,19 \\
\hline $\operatorname{PS10V}(g)$ & 34,72 & 27,30 & 26,78 & 29,15 & 24,17 & 25,36 \\
\hline P100S (g) & 20,96 & 19,99 & 17,87 & 19,49 & 19,23 & 17,43 \\
\hline IG (\%) & 75,96 & 75,36 & 80,23 & 73,52 & 70,93 & 75,28 \\
\hline PG (kg/ha) & $2.143,37$ & $2.033,50$ & $1.802,19$ & $1.829,80$ & $1.698,90$ & $1.884,20$ \\
\hline
\end{tabular}

C10V - Comprimento médio de 10 vagens; P10V - Peso de 10 vagens; NS10V - Número de sementes de 10 vagens; PS10V - Peso de sementes de 10 vagens; P100S - Peso de 100 sementes; IG - Índice de grãos (\%); PG - Produtividade de grãos, baseada em análises conjuntas/ano. 
Tabela 3. Dados de produtividade da cultivar Miranda IPA 207 e de outras duas cultivares, avaliados em dois anos e três Regiões Edafoclimáticas de Pernambuco.

Primeiro Ano: 2009*

\begin{tabular}{|c|c|c|c|c|c|}
\hline \multirow{3}{*}{ Região Edafoclimática } & \multirow{3}{*}{ Local } & \multirow{2}{*}{\multicolumn{3}{|c|}{ Produtividade média (kg/ha) }} & \multirow{3}{*}{$\mathrm{CV}(\%)$} \\
\hline & & & & & \\
\hline & & Miranda IPA 207 & Patativa & BRS Paraguaçu & \\
\hline Agreste & Estação Experimental de Arcoverde & $3.359,38 \mathrm{a}$ & $2.740,63 \mathrm{abc}$ & $1.615,63 \mathrm{~cd}$ & 19,35 \\
\hline Sertão & Estação Experimental de Belém do São Francisco & $2.743,75 \mathrm{a}$ & $2.067,19 \mathrm{ab}$ & $1.875,00 \mathrm{ab}$ & 20,47 \\
\hline Mata Norte pernambucana & Estação Experimental de Itapirema & $1.362,00 \mathrm{a}$ & $1.475,00 \mathrm{a}$ & $1.437,00 \mathrm{a}$ & 20,78 \\
\hline Mata Sul pernambucana & Estação Experimental de Vitória de Santo Antão & $1.656,28 \mathrm{ab}$ & $1.567,20 \mathrm{ab}$ & $1.835,95 \mathrm{ab}$ & 13,42 \\
\hline \multirow{3}{*}{ Região Edafoclimática } & \multirow{3}{*}{ Local } & \multicolumn{4}{|c|}{ Segundo Ano: 2010* } \\
\hline & & \multicolumn{3}{|c|}{ Produtividade média (kg/ha) } & \\
\hline & & Miranda IPA 207 & Patativa & BRS Paraguaçu & $8(70)$ \\
\hline Sertão & Estação Experimental de Belém do São Francisco & $3.578,50 \mathrm{a}$ & $2.772,25 \mathrm{ab}$ & $3.059,75 \mathrm{ab}$ & 15,06 \\
\hline Mata Norte pernambucana & Estação Experimental de Itapirema & $1.829,80 \mathrm{a}$ & $1.698,90 \mathrm{a}$ & $1.884,20 \mathrm{a}$ & 18,56 \\
\hline Mata Sul pernambucana & Estação Experimental de Vitória de Santo Antão & $1.611,00 \mathrm{a}$ & $1.478,30 \mathrm{a}$ & $1.567,50 \mathrm{a}$ & 15,41 \\
\hline
\end{tabular}

*Médias seguidas das mesmas letras na linha não diferem entre si pelo teste de Tukey, a 5\% de probabilidade.

feijão-caupi. Barros et al. (2009) avaliaram a supressividade de solos à rizoctoniose do feijão-caupi. Athayde Sobrinho (2004) detectou reduzida presença de Macrophomina phaseolina nas amostras coletadas; entre elas havia sementes de feijão-caupi cultivar IPA 207, em municípios do Estado de Pernambuco.

Em trabalhos desenvolvidos na área do melhoramento de plantas, a cultivar IPA 207 foi avaliada em Campinas/ SP (MELO et al., 2011b) e Lagoa Seca/PB (SANTOS et al., 2009), em períodos distintos, ambos visando à caracterização morfoagronômica e a indicação para uso pelos agricultores. Os resultados relevantes obtidos com essa cultivar, para as condições de Campinas, indicam que ela foi a mais precoce entre as estudadas, com abertura da flor aos 58 dias e maturação da primeira vagem aos 73 dias da semeadura. Outros resultados significativos foram o maior comprimento do caule, largura e número de lóculos por vagem; estando de acordo com os dados aqui relatados para IPA 207. Por outro lado, nas condições da microrregião do Brejo Paraibano, entre as cultivares testadas, L 281.005 obteve resposta relevante para número de vagens por planta, comprimento de vagem, produtividade de grãos e comportamento produtivo, em relação às demais e aos materiais tradicionalmente cultivados na região, podendo ser utilizada no desenvolvimento da economia local. Leite $(2009,2012)$ inicialmente analisou a variabilidade genética e avaliou a resistência de cultivares de feijão-caupi ao caruncho (Callosobruchus maculatus (Fabr.)), verificando que L.281.005 (IPA 207) apresentou uma média de 50 insetos emergidos, denotando certa susceptibilidade a esse inseto. Ainda nessa linha de pesquisa, a autora estudou a diversidade genética associada à resistência ao caruncho em feijão-caupi por meio de marcadores moleculares, quando encontrou resultados semelhantes.

Em fitotecnia, Silva (2002) estudou os níveis de fósforo, fases de colheita e condições de armazenamento na manutenção das qualidades fisiológicas de sementes de feijão-macassar, utilizando a linhagem L. 281.005, concluindo que a aplicação de fósforo não promoveu aumento da produtividade, e que as sementes mantiveram boas condições de armazenamento por um período de até nove meses em condições de temperatura ambiente $\left(28^{\circ} \mathrm{C}\right)$ e de até dois anos em câmara de conservação a $12{ }^{\circ} \mathrm{C}$, sem haver perda das qualidades fisiológicas, podendo também ser armazenadas em lata, sacos de nylon ou de algodão.

\section{Referências}

ANDRIÓN, E. E. B. Supressividade natural de solos do nordeste brasileiro à murcha-de-fusário e rizoctoniose do caupi. 2009. 85 f. Tese (Doutorado em Fitopatologia)-Universidade Federal Rural de Pernambuco, Recife, 2009.

ATHAYDE SOBRINHO, C. Patossistema caupi x Macrophomina phaseolina: método de detecção em sementes, esporulação e controle do patógeno. 2004. 147 f. Tese (Doutorado em Fitopatologia)-Escola Superior de Agronomia Luiz de Queiroz, Universidade de São Paulo, Piracicaba, 2004.

BARROS, A. P. O. et al. Supressividade de solos à rizoctoniose do caupi. In: JORNADA DE ENSINO, PESQUISA E EXTENSÃO - JEPEX, 9., 2009, Recife. Anais... Recife: UFRPE, 2009.

FAOSTAT. FAO Statistics Division 2012. Disponível em: <http:// faostat.fao.org>. Acesso em: 02 jan. 2012.

FERREIRA, M.F.;ANDRIÓN, E. E. B.; MICHEREFF, S. J.Estabilidade da supressividade de solos à rizoctoniose do caupi. In: JORNADA DE ENSINO, PESQUISA E EXTENSÃO - JEPEX, 9., 2009, Recife. Anais... Recife: UFRPE, 2009.

INSTITUTO BRASILEIRO DE GEOGRAFIA E ESTATÍSTICA - IBGE. Levantamento Sistemático da Produção Agrícola. Disponível em: $<$ http://www.sidra.ibge.gov.br/bda/tabela/ protabl.asp? $\mathrm{c}=1618 \& \mathrm{z}=\mathrm{t} \& \mathrm{o}=1 \& \mathrm{i}=\mathrm{P}>$. Acesso em: 01 fev. 2012.

LEITE, N. G. A. Diversidade genética associada à resistência ao caruncho Callosobruchus maculatus (Fabr.) em Vigna unguiculata (L.) Walp. por meio de marcadores moleculares. 2012. 64 f. Dissertação(Mestrado)-Centro de Ciências Biológicas, Universidade Federal de Pernambuco, Recife, 2012. 
LEITE, N. G. A. Análise da variabilidade genética e avaliação da resistência de cultivares de feijão-caupi (Vigna unguiculata $(\mathbf{L}$.) Walp) ao caruncho (Callosobruchus maculatus Fabr.). 2009. $45 \mathrm{f}$. Monografia (Graduação)-Centro de Ciências Biológicas, Universidade Federal de Pernambuco, Recife, 2009.

MELO, R. A. et al. Caracterização molecular de genótipos de feijãocaupi. Horticultura Brasileira, Brasilia, v. 29, p. S84-S91, 2011a.

MELO, R. A. et al. Caracterização morfo-agronômica de genótipos de feijão-caupi. Horticultura Brasileira, Brasilia, v. 29, p. S3365-S3372, 2011b.

OLIVEIRA, A. L. et al. Efeito de BAP e 2,4 - D na formação de calos em diferentes explantes de feijão-caupi. In: CONGRESSO
NACIONAL DE FEIJÃO-CAUPI; REUNIÃO NACIONAL DE FEIJÃO-CAUPI, 6., 2006, Teresina. Anais... Teresina, 2006.

SANTOS, J. F. et al. Novas variedades de caupi para a microrregião do Brejo Paraibano1. Tecnologia \& Ciência Agropecuária, João Pessoa, v. 3, n. 3, p. 7-12, set. 2009.

SILVA, G. H. Níveis de fósforo, fases de colheita e condições de armazenamento na manutenção das qualidades fisiológicas de sementes de feijão-macassar. 2002.37 f. Monografia (Graduação)Universidade Federal Rural de Pernambuco, Recife, 2002.

SILVA, T. H. C. A.; MICHEREFF, S. J. Indução da supressividade pela rotação de culturas no manejo da rizoctoniose do caupi. In: JORNADA DE ENSINO, PESQUISA E EXTENSÃO - JEPEX, 10., 2010, Recife. Anais... Recife: UFRPE, 2010. 